\title{
Seismic data reconstruction with application to SRME for walkaway VSP data
}

Einar Otnes (WesternGeco) and Ketil Hokstad (StatoilHydro)

\section{SUMMARY}

Interferometry is used to reconstruct surface data from Walkaway VSP data. Together with a common receiver gather of a WVSP experiment we formulate a data-driven surface demultple scheme for WVSP data. The theory will be presented together with real data examples from the Nordkapp basin in the Barents Sea, an area well known for its complex geological structures. 